\title{
Pós covid-19: as sequelas deixadas pelo Sars-Cov-2 e o impacto na vida das pessoas acometidas
}

\section{Post covid-19: the sequels left by Sars-Cov-2 and the impact on the life of the those affected}

DOI: $10.46919 / \operatorname{archv} 2 n 3-021$

Recebimento dos originais: 01/05/2021

Aceitação para publicação: 30/06/2021

Thalia Lima Nogueira

Acadêmica do Curso de Enfermagem da Faculdade Aggeu Magalhães - FAMA e membro da liga acadêmica de Ensino em saúde e pesquisa - LAESP,Serra Talhada,Pernambuco , Brasil

Shirley Daiane Alves da Silva

Acadêmica do Curso de Enfermagem da Faculdade Aggeu Magalhães - FAMA e membro da liga acadêmica de Ensino em saúde e pesquisa - LAESP,Serra Talhada,Pernambuco , Brasil.

\section{Lidiane Hilário da Silva}

Acadêmica do Curso de Enfermagem da Faculdade Aggeu Magalhães - FAMA e membro da liga acadêmica de Ensino em saúde e pesquisa - LAESP,Serra Talhada,Pernambuco , Brasil.

Maria Vitória Silva Leite

Acadêmica do Curso de Enfermagem da Faculdade Aggeu Magalhães - FAMA e membro da liga acadêmica de Ensino em saúde e pesquisa - LAESP,Serra Talhada,Pernambuco , Brasil.

\section{José Filipe Alves da Rocha}

Acadêmico do Curso de Enfermagem da Faculdade Aggeu Magalhães - FAMA e membro da liga acadêmica de Ensino em saúde e pesquisa - LAESP,Serra Talhada,Pernambuco , Brasil.

\section{Raul Sousa Andreza}

Biomédico e Docente da Faculdade Aggeu Magalhães e Orientador da Liga acadêmica de Ensino em Saúde e Pesquisa - LAESP ,Serra Talhada,Pernambuco,Brasil.

\section{RESUMO}

Por meio da sua facilidade de transmissão e altas taxas de mortalidade, o SARS-CoV-2 até 2021 já infectou mais de 15 milhões de brasileiros. Além do período de incubação e manifestação dos sinais clínicos, a COVID-19 acarreta em muito mais sofrimento pela permanência de sequelas que retardam esse quadro, causando infecção multissistêmica pelo acometimento de tecidos vitais como o cardiológico, muscular, neurológico e psicológico. Sendo necessário o manejo por meio da reabilitação que tem por finalidade proporcionar a reversão e melhora funcional, física e emocional dos acometidos. O presente estudo teve por objetivo investigar as principais sequelas acarretadas pela COVID-19 nos pacientes em reabilitação, bem como a análise do impacto na qualidade de vida e bem-estar desses indivíduos. Com relação aos aspectos metodológicos, trata-se de uma revisão bibliográfica sistemática em que foram realizadas buscas na literatura e selecionados 26 estudos que atendiam os critérios de inclusão, por meio das bases de dados do Google Acadêmico, SciELO e PubMed publicados no período de 2020 a 2021, nos idiomas português e inglês. Mediante análise do material encontrado, as afecções referentes ao sistema pulmonar são as mais evidentes por representar o órgão alvo do vírus, comumente desencadeando sintomas como dispneia, fadiga e em quadros clínicos mais graves a fibrose pulmonar. $\mathrm{O}$ acometimento cardiovascular resulta em lesão 
cardíaca aguda, miocardite, inflamação vascular e arritmias cardíacas, enquanto que as disfunções olfativas e gustativas pertinentes ao sistema neurológico são amplamente relatadas. As sequelas musculoesqueléticas envolvem fraqueza ocasionada pela sarcopenia e perda de força muscular em resposta a infecção viral, imobilidade e nutrição insuficiente. O abalo psicológico e emocional surgem em decorrência do processo de isolamento social além do medo pelo potencial risco de morte, deteriorando a saúde mental desses indivíduos pela ansiedade, depressão e estresse pós-traumático. A reabilitação exige atuação de uma equipe multidisciplinar por medidas fisioterapêuticas que possibilitem a reintegração social do indivíduo e considerável melhora em sua qualidade de vida de forma independente. Portanto, é nítida a necessidade da continua produção cientifica de múltiplas perspectivas sobre temáticas referentes à COVID-19, sobretudo pela sua constante evolução.

Palavras-chave: SARS-CoV-2. COVID-19. Sequelas. Reabilitação.

\begin{abstract}
Through its facility of transmission and high mortality rates, SARS-CoV-2 until 2021 has already infected more than 15 million Brazilians. Besides the incubation period and the manifestation of clinical signs, COVID-19 causes much more suffering due to the permanence of sequelae that delay this scenario, causing multisystemic infection by affecting vital tissues such as cardiological, muscular, neurological, and psychological. It is necessary to manage the disease through rehabilitation, which aims to provide the reversal and functional, physical, and emotional improvement of those affected. The present study aimed to investigate the main sequels caused by COVID-19 in patients in rehabilitation, as well as to analyze the impact on the quality of life and well-being of these individuals. Regarding the methodological aspects, this is a systematic bibliographic review in which literature searches were conducted and 26 studies that fulfilled the inclusion criteria were selected, through the Google Academic, SciELO and PubMed databases published in the period from 2020 to 2021, in Portuguese and English. By analyzing the material found, the disorders related to the pulmonary system are the most evident since it represents the target organ of the virus, commonly triggering symptoms such as dyspnea, fatigue and, in more severe clinical cases, pulmonary fibrosis. The cardiovascular involvement results in acute cardiac injury, myocarditis, vascular inflammation, and cardiac arrhythmias, while olfactory and gustatory dysfunctions pertaining to the neurological system are widely reported. Musculoskeletal sequelae involve weakness occasioned by sarcopenia and loss of muscle strength in response to viral infection, immobility, and insufficient nutrition. Psychological and emotional distress arise from the process of social isolation and fear of the potential risk of death, deteriorating the mental health of these individuals through anxiety, depression, and posttraumatic stress. Rehabilitation requires the action of a multidisciplinary team for physiotherapeutic measures that enable the social reintegration of the individual and considerable improvement in their quality of life independently. Therefore, there is a clear need for continuous scientific production of multiple perspectives on themes related to COVID-19, especially because of its constant evolution.
\end{abstract}

Keywords: SARS-CoV-2. COVID-19. Sequels. Rehabilitation.

\title{
1 INTRODUÇÃO
}

Há séculos as mais diversas enfermidades afligem a humanidade dentre as quais se destacam as doenças virais, que já em épocas remotas deixavam um rastro sangrento e obscuro que surpreendentemente com traços similares e altos índices de contaminação tem ressurgido em pleno século 21 . O vírus Influenza representa um destes patógenos que acometeu mais de 53 mil pessoas no Brasil entre os anos de 2009 e 2010, especificamente a influenza A que tem por principais características o comprometimento do trato 
respiratório causando uma infecção aguda, alto grau de transmissão por gotículas facilmente dissipadas no ar e altamente passível de mutações gênicas (NOGUEIRA; SILVA, 2020).

Aspectos bastante semelhantes ao novo vírus identificado por SARS-CoV-2 que já infectou até o mês de maio de 2021 mais de 15 milhões de brasileiros, seus primeiros registros foram observados na cidade de Wuhan na China e por meio do seu elevado grau de propagação a Organização Mundial da Saúde (OMS) em fevereiro de 2020 viu-se no dever de declarar alerta pandêmico e denominou esta nova patologia de Covid-19 (Coronavírus Disease -2019), (SILVA; PINA; ORMOND, 2021; BRASIL, 2020).

O SARS-CoV-2 pertence ao gênero betacoronavírus em que também se encontram o vírus SARSCoV e MERS-CoV responsáveis por causar, respectivamente, Síndrome Respiratória Aguda Grave e a Síndrome Respiratória do Oriente Médio, considerados as forma mais virulentas da família Coronaviridae. Dessa forma, além de ser notificado como um dos sete tipos de coronavírus atualmente conhecidos, o SARS-CoV-2 é o agente etiológico da COVID-19 e apresenta em seu material genético RNA de fita simples circundado por uma cápsula lipoproteica, que facilmente se liga a enzima ACE2 (angiotensin-converting enzyme 2, traduzido por enzima de conversão de angiotensina tipo 2) expressa na superfície de diversas células do corpo como no epitélio do sistema respiratório, facilitando a entrada do patógeno no organismo humano (NOGUEIRA; SILVA, 2020).

A via de transmissão do vírus, se dar através do contato por gotículas respiratórias e possui um período de incubação de aproximadamente seis dias. Vale ressaltar que não existe estado crônico da infecção, pois os humanos não são seus hospedeiros naturais. O vírus é eliminado do corpo entre duas a quatro semanas e caso não encontre um hospedeiro, o mesmo não se multiplica. Os sintomas podem aparecer em até onze dias e em casos leves podem ocorrer: febre, tosse, fadiga, hemoptise e dispneia. Em casos mais graves, existe a possibilidade de uma pneumonia, síndrome do desconforto respiratório (SDRA), problemas cardíacos agudos e até falência múltipla dos órgãos (NUNES et al., 2020; SILVA; PINA; ORMOND, 2021).

Por se instalar inicialmente nos pulmões, as sequelas referentes ao sistema respiratório são mais significantes e evidentes em que se destacam a redução do volume e capacidade pulmonar, dificuldades na prática de exercícios físicos resultando em perda funcional, cansaço, fadiga, e dispneia mesmo em repouso ou na execução de atividades de vida diária (AVDs). Sendo possível o acometimento de outros sistemas do organismo como o cardiovascular, acarretando em lesão cardíaca aguda, miocardite, inflamação vascular e arritmias cardíacas. No tangente as sequelas neurológicas são bastante expressivas as que afetam o trato olfatório causando hiposmia (diminuição do olfato) já relatado por diversos pacientes pós-covid-19 e bem como disgeusia (distorção ou diminuição do paladar). Contudo, tais progressos dependem não só da gravidade e extensão da lesão promovida pela infecção viral como também da presença de comorbidades (CAMPOS et al., 2020; AVILA, PEREIRA e TORRES, 2020). 
Dessa forma, baseando-se nas informações supracitadas surgiu a necessidade de investigação referente às principais sequelas acarretadas pela COVID-19 nos pacientes em reabilitação, bem como a análise do impacto na qualidade de vida e bem-estar desses indivíduos.

\section{METODOLOGIA}

O presente estudo trata-se de uma revisão bibliográfica sistemática, em que foram realizadas buscas na literatura com os seguintes descritores: COVID-19, SARS-CoV-2, sequelas e reabilitação pós-Covid19, a fim de analisar quais atendiam ao tema proposto e aos critérios de inclusão e posteriormente aos critérios de exclusão. Foram selecionados 26 estudos que incluíram artigos, manuais técnicos e boletim epidemiológico durante o mês de maio de 2021 nas bases de dados do Google Acadêmico, SciELO e PubMed publicados no período de 2020 a 2021 nos idiomas português e inglês, como caracterizado na figura I.

Figura I- Fluxograma de seleção dos estudos.

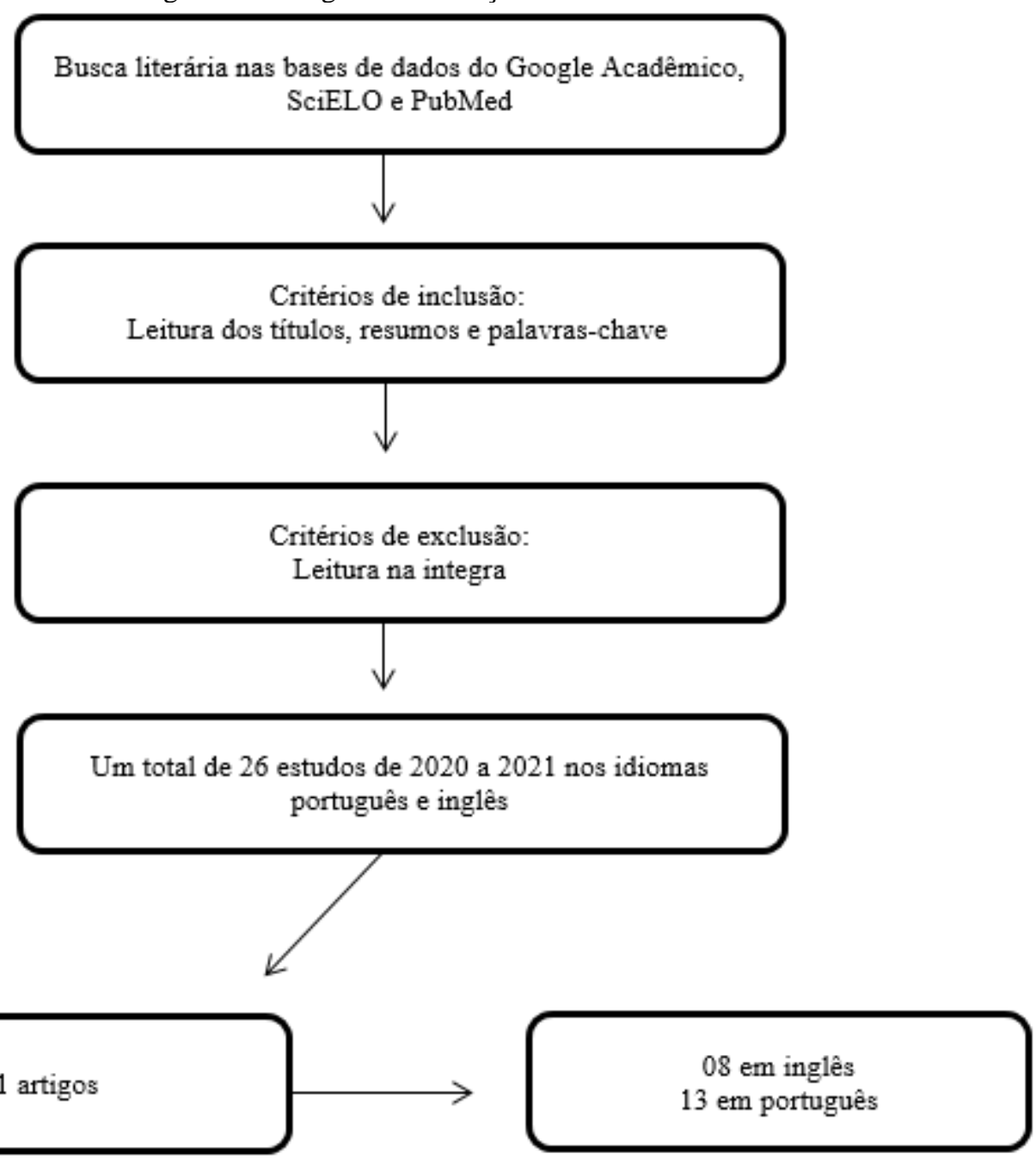




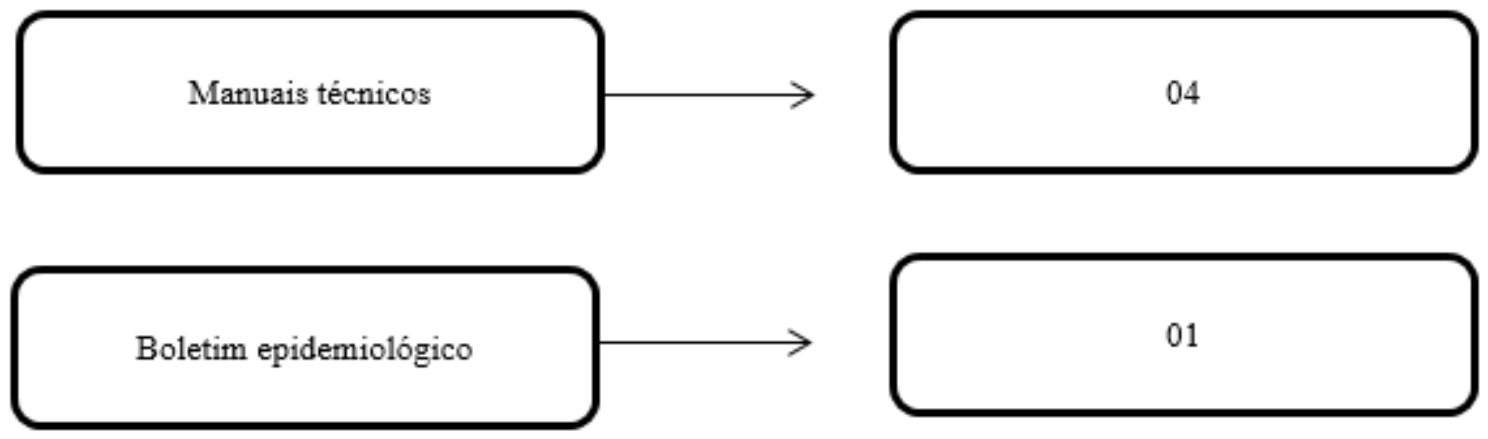

Fonte: Autoria própria.

De acordo com a leitura e analise realizada, foram selecionados 21 artigos que apresentavam características compatíveis à explorada em nosso estudo, como expresso no quadro I.

Quadro I- Descrição dos artigos selecionados para revisão sistemática.

\begin{tabular}{|c|c|c|c|c|}
\hline ANO & AUTOR & OBJETIVO GERAL & MÉTODO & RESULTADOS \\
\hline 2020 & $\begin{array}{l}\text { ALMEIDA; } \\
\text { CHEHTER. }\end{array}$ & $\begin{array}{l}\text { Revisar a r literatura } \\
\text { relacionada } \\
\text { prevalência dos sintomas } \\
\text { gastrintestinais, e verificar se } \\
\text { é possível a transmissão } \\
\text { fecal-oral da doença. }\end{array}$ & $\begin{array}{l}\text { Busca literária pelo } \\
\text { método PRISMA. }\end{array}$ & $\begin{array}{l}\text { A prevalência de sintomas gastrintestinais } \\
\text { variou entre } 6,8 \% \text { e } 61,3 \% \text {, sendo eles } \\
\text { diarreia }(8,14 \% \text { a } 33,7 \%) \text {, náusea/vômito } \\
(1,53 \% \text { a } 26,4 \%) \text {, anorexia }(12,1 \% \text { a } 40,0 \%) \\
\text { e dor abdominal }(0 \% \text { a } 14,5 \%) \text {. Contudo, os } \\
\text { resultados de prevalência e a possibilidade de } \\
\text { transmissão fecal-oral foram variados, } \\
\text { necessitando de estudos maiores para } \\
\text { conclusões mais assertivas. }\end{array}$ \\
\hline 2020 & ACOSTA et al. & $\begin{array}{l}\text { Aborda aspectos das } \\
\text { atividades humanas que } \\
\text { afetam o ambiente e podem } \\
\text { influenciar na transmissão e } \\
\text { spillover de coronavírus. E os } \\
\text { riscos do coronavírus retornar } \\
\text { da cidade para a selva, em } \\
\text { preparação para um novo } \\
\text { retorno pandêmico. }\end{array}$ & Ensaio científico. & $\begin{array}{l}\text { Revelou a necessidade de novos meios de } \\
\text { produção sustentáveis que não coloque em } \\
\text { risco o futuro das gerações seguintes e } \\
\text { mantenha o equilíbrio entre o meio ambiente } \\
\text { e suas espécies. }\end{array}$ \\
\hline 2020 & CARFI et al. & $\begin{array}{l}\text { Investigar sintomas } \\
\text { persistentes pós-fase aguda } \\
\text { da COVDI-19. }\end{array}$ & $\begin{array}{l}\text { Pesquisa de campo por } \\
\text { meio da aplicação de } \\
\text { um questionário } \\
\text { padronizado em um } \\
\text { sistema estruturado de } \\
\text { coleta de dados } \\
\text { eletrônicos. }\end{array}$ & $\begin{array}{l}\text { Pacientes que se recuperaram de COVID-19, } \\
87,4 \% \text { relataram persistência de pelo menos } \\
01 \text { sintoma, particularmente fadiga e } \\
\text { dispneia. }\end{array}$ \\
\hline 2020 & CAMPOS et al. & $\begin{array}{l}\text { Explorar a utilidade do } \\
\text { indicador DALY na captação } \\
\text { de forma mais efetiva dos } \\
\text { efeitos da COVID-19, } \\
\text { considerando aspectos como } \\
\text { sua gravidade, duração e } \\
\text { potencial de gerar } \\
\text { complicações crônicas que } \\
\text { aumentarão as demandas no } \\
\text { Sistema Único de Saúde } \\
\text { (SUS). }\end{array}$ & Ensaio bibliográfico. & $\begin{array}{l}\text { Ressaltou a importância de caracterizar a } \\
\text { história natural da doença e estimar } \\
\text { indicadores como o YLD, que considerem a } \\
\text { alta carga de morbidade no planejamento de } \\
\text { estratégias para lidar com as consequências } \\
\text { da COVID-19 pós-pandemia. }\end{array}$ \\
\hline
\end{tabular}




\begin{tabular}{|c|c|c|c|c|}
\hline 2020 & DANIEL et al. & $\begin{array}{l}\text { Reflexão sobre os cuidados } \\
\text { dado aos pacientes pós- } \\
\text { COVID19. }\end{array}$ & $\begin{array}{l}\text { Revisão bibliográfica } \\
\text { de modo a promover } \\
\text { reflexão sobre tema. }\end{array}$ & $\begin{array}{l}\text { Evidenciou a necessidade de atuação de uma } \\
\text { equipe multidisciplinar na reabilitação pós- } \\
\text { COVID19, pela implantação de protocolos e } \\
\text { rotinas além do cuidado integral. }\end{array}$ \\
\hline 2020 & GIACOMELLI et al. & $\begin{array}{l}\text { Investigação dos distúrbios } \\
\text { olfativos e do paladar em } \\
\text { pacientes com infecção aguda } \\
\text { respiratória do SARS-CoV-2. }\end{array}$ & Um estudo transversal. & $\begin{array}{l}\text { Pelo menos } 33,9 \% \text { dos entrevistados } \\
\text { relataram pelo menos } 01 \text { distúrbio gustativo } \\
\text { ou olfatório e } 11 \quad(18,6 \%) \text { ambos. Doze } \\
\text { pacientes (20,3\%) apresentaram os sintomas } \\
\text { antes da internação hospitalar, enquanto } 08 \\
(13,5 \%) \text { experimentaram os sintomas } \\
\text { durante a internação. }\end{array}$ \\
\hline 2020 & GREVE et al. & $\begin{array}{lrr}\text { Realizar uma análise } \\
\text { reflexiva no que tange ao } \\
\text { impacto da COVID-19 nos } \\
\text { sistemas imunológico, } \\
\text { neuromuscular } r \text { e } \\
\text { musculoesquelético e no } \\
\text { processo de reabilitação. }\end{array}$ & $\begin{array}{l}\text { Trata-se de uma análise } \\
\text { reflexiva. }\end{array}$ & $\begin{array}{l}\text { Evidenciou as sequelas musculoesqueléticas } \\
\text { dos pacientes vitimas da COVID-19 em } \\
\text { decorrência do processo inflamatório e perda } \\
\text { de massa muscular causada pela imobilidade, } \\
\text { que geram incapacidades motoras ainda não } \\
\text { quantificáneis, além da necessidade de } \\
\text { reabilitação dos pacientes. }\end{array}$ \\
\hline 2020 & GUAN et al. & $\begin{array}{llrr}\text { Avaliar o } & \text { espectro } & \text { de } \\
\text { comorbidades } & \text { e seu impacto } \\
\text { no desfecho } & \text { clínico em } \\
\text { pacientes com } & \text { doença } \\
\text { coronavírus } & 2019 & \text { (COVID- } \\
19) . & & \end{array}$ & $\begin{array}{lll}\text { Estudos } & \text { de } & \text { caso } \\
\text { retrospectivos. } & \end{array}$ & $\begin{array}{l}\text { As comorbidades estão presentes em cerca de } \\
\text { um quarto dos pacientes com COVID-19 na } \\
\text { China, e predispõe a piores resultados } \\
\text { clínicos. }\end{array}$ \\
\hline 2020 & HUANG et al. & 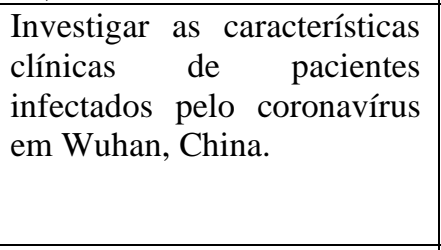 & Pesquisa prospectiva. & $\begin{array}{l}\text { Pelo menos } 27(66 \%) \text { pacientes tiveram } \\
\text { exposição direta ao mercado de frutos do } \\
\text { mar. Os sintomas mais comuns no início da } \\
\text { doença foram febre }(98 \%) \text {, tosse }(76 \%) \text { e } \\
\text { mialgia ou fadiga }(44 \%) \text {. Mais da metade dos } \\
\text { pacientes }(55 \%) \text { desenvolveram dispneia. }\end{array}$ \\
\hline 2020 & ISER et al. & $\begin{array}{l}\text { Descrever os sinais } \text { e } \\
\text { sintomas mais frequentes na } \\
\text { infecção pelo vírus da } \\
\text { síndrome respiratória aguda } \\
\text { grave } \\
\text { coronavírus } 2 \text { (SARS-CoV- } \\
\text { 2). }\end{array}$ & $\begin{array}{l}\text { Revisão narrativa da } \\
\text { literatura. }\end{array}$ & $\begin{array}{l}\text { O espectro da doença clínica mostrou-se } \\
\text { variado; febre, tosse e dispneia foram os } \\
\text { sinais/ sintomas mais frequentes, sintomas } \\
\text { gastrointestinais e alteração de olfato ou } \\
\text { paladar têm sido relatados entre casos leves. } \\
\text { A dispneia foi frequente entre casos graves e } \\
\text { com evolução ao óbito. }\end{array}$ \\
\hline 2021 & LUO et al. & $\begin{array}{l}\text { Explorar os fatores de risco } \\
\text { associados à infecção de } \\
\text { contatos próximos. }\end{array}$ & $\begin{array}{l}\text { Análise de regressão } \\
\text { logística. }\end{array}$ & $\begin{array}{l}\text { Entre os diferentes modos de contato, } 53 \\
\text { contatos domiciliares foram os mais } \\
\text { perigosos na infeçãa de COVID-19, com } \\
\text { uma incidência de } 10,2 \% \text {. Sendo que a } \\
\text { proporção de infecções assintomáticas e } \\
\text { leves é responsável por quase metade dos } \\
\text { casos confirmados entre contatos próximos. }\end{array}$ \\
\hline 2020 & MORALES et al. & $\begin{array}{l}\text { Resumir as características } \\
\text { clínicas, laboratoriais e de } \\
\text { imagem da COVID } 19 .\end{array}$ & $\begin{array}{l}\text { Revisão sistemática e } \\
\text { meta-análise } \\
\text { (PRISMA). }\end{array}$ & $\begin{array}{l}\text { Para } 656 \text { pacientes, febre }(88,7 \%) \text {, tosse } \\
(57,6 \%) \text { e dispneia }(45,6 \%) \text { foram as } \\
\text { manifestaçôes mais prevalentes. Entre os } \\
\text { pacientes, } 20,3 \% \text { necessitaram de unidade de } \\
\text { terapia intensiva (UTI), } 32,8 \% \text { apresentaram } \\
\text { síndrome do desconforto respiratório agudo } \\
\text { (SDRA). }\end{array}$ \\
\hline 2021 & MOURA et al. & $\begin{array}{l}\text { Analisar a limitada evidência } \\
\text { científica atual acerca } \\
\text { relevância clínica } \\
\text { sequelas da COVID-19, em } \\
\text { particular do foro respiratório } \\
\text { e cardíaco. }\end{array}$ & Ensaio bibliográfico. & $\begin{array}{l}\text { Foi possível encontrar referências sobre as } \\
\text { sequelas respiratórias e cardíacas. A doença } \\
\text { intersticial pulmonar, a doença } \\
\text { tromboembólica crónica com hipertensão } \\
\text { pulmonar, a miocardite, as arritmias } \\
\text { cardíacas, a insuficiência cardíaca aguda e as } \\
\text { síndromes coronárias agudas surgem como } \\
\text { as principais entidades referidas no pós- } \\
\text { Covid. }\end{array}$ \\
\hline
\end{tabular}




\begin{tabular}{|c|c|c|c|c|}
\hline 2020 & NOGUEIRA; SILVA & $\begin{array}{l}\text { Investigar a origem evolutiva } \\
\text { deste vírus, suas caraterísticas } \\
\text { biológica e ecológica, sua } \\
\text { forma de transmissão à } \\
\text { população, bem como os } \\
\text { principais agravos que esta } \\
\text { doença pode trazer. }\end{array}$ & $\begin{array}{l}\text { Pesquisa bibliográfica } \\
\text { do tipo qualitativa. }\end{array}$ & $\begin{array}{l}\text { Expressou semelhanças com as infecções } \\
\text { respiratórias causadas por SARS e MERS- } \\
\text { CoV em } 2012 \text {, fato que leva a crer que o Sars- } \\
\text { cov2 possa ter características parecidas de } \\
\text { transmissibilidade e origem evolutiva com } \\
\text { estes vírus. Estudos realizados comparando o } \\
\text { genoma do Sars-cov2 com genoma de } \\
\text { coronavírus de morcegos da espécie } \\
\text { Rhinolophus affinis demostraram que } 96 \% \\
\text { deste vírus apresentam proximidade. }\end{array}$ \\
\hline 2020 & NUNES et al. & \begin{tabular}{lll} 
Descrever & os & \multicolumn{2}{c}{ impactos } \\
neurológicos & associados & à \\
COVID-19. & &
\end{tabular} & Revisão de literatura. & $\begin{array}{l}\text { O Sars-cov-2 possui capacidade de } \\
\text { neuroinvasão. A agressividade dos sintomas } \\
\text { pode variar de sintomas mais leves até } \\
\text { predispor a doenças cerebrovasculares } \\
\text { agudas, em especial, nos pacientes com } \\
\text { comorbidades. Em pacientes hipertensos os } \\
\text { sintomas respiratórios podem ser } \\
\text { amenizados, acarretando maior atenção para } \\
\text { investigaçãa e diagnóstico. }\end{array}$ \\
\hline 2020 & $\begin{array}{l}\text { OLIVEIRA; LUCAS; } \\
\text { IQUIAPAZA. }\end{array}$ & $\begin{array}{llrr}\text { Analisar a } & \text { pandemia } & \text { da } \\
\text { Covid-19 e } & \text { o } & \text { que } & \text { temos } \\
\text { (re)aprendido } & \text { com } & \text { a } \\
\text { experiência } & \text { mundial } & \text { para } \\
\text { adoção das } & \text { medidas } & \text { de } \\
\text { prevenção. } & & \end{array}$ & Coleta de dados. & $\begin{array}{l}\text { Apontou que o caminho para a redução da } \\
\text { velocidade de circulação do vírus, o controle } \\
\text { e queda do número de casos e óbitos } \\
\text { decorrentes dessa pandemia só poderá ser } \\
\text { alcançado com adoção em massa de medidas } \\
\text { fundamentais que incluem higienização das } \\
\text { mãos, uso do álcool em gel, etiqueta } \\
\text { respiratória, limpeza de superfícies, evitar } \\
\text { aglomerações e distanciamento social. }\end{array}$ \\
\hline 2020 & PERES, A.C. & $\begin{array}{l}\text { Relatar experiência r de } \\
\text { pessoas acometidas pela } \\
\text { COVID-19 em recuperação e } \\
\text { evidenciar r sintomas } \\
\text { persistentes da síndrome pós- } \\
\text { COVID. }\end{array}$ & Relato de experiência. & $\begin{array}{l}\text { O relato expressou o comprometimento da } \\
\text { realização de atividades básicas do cotidiano } \\
\text { em indivíduos em recuperação da COVID- } \\
19 \text {, pertinente aos sintomas da síndrome pós- } \\
\text { COVID, dando ênfase a fadiga, enjoo, mal- } \\
\text { estar. }\end{array}$ \\
\hline 2020 & PIMENTEL et al. & $\begin{array}{l}\text { Compreender os aspectos de } \\
\text { disseminação do SARS-CoV- } \\
2 \text { e sua repercussão } \\
\text { internacional com desfechos } \\
\text { sociais, econômicos e de } \\
\text { saúde muito deletérios aos } \\
\text { seres humanos e aos países, } \\
\text { em especial naqueles em } \\
\text { desenvolvimento. }\end{array}$ & Ensaio bibliográfico. & $\begin{array}{l}\text { Todos os seres humanos são susceptíveis a } \\
\text { hospedar o SARS-CoV-2, entretanto, aqueles } \\
\text { com comorbidades, doenças crônicas e com } \\
\text { idade maior do que } 60 \text { anos são mais } \\
\text { facilmente afetados pela gravidade da doença } \\
\text { COVID-19. Ainda não há tratamento } \\
\text { específico e esforços mundiais estão sendo } \\
\text { realizados para o desenvolvimento de } \\
\text { vacinas. }\end{array}$ \\
\hline 2021 & $\begin{array}{ll}\text { SILVA; } & \text { PINA; } \\
\text { ORMOND. } & \end{array}$ & $\begin{array}{l}\text { Análise da reabilitação pós } \\
\text { covid-19 e as principais } \\
\text { sequelas } \\
\text { doença. }\end{array}$ & $\begin{array}{lrl}\begin{array}{l}\text { Estudo de } \\
\text { bibliográfica. }\end{array} & \\
\text { revisão }\end{array}$ & $\begin{array}{l}\text { Ressaltou a importância da reabilitação } \\
\text { respiratória nos pacientes em estado grave } \\
\text { com disfunção respiratória após a alta, e a } \\
\text { evolução para má aptidão física, falta de ar } \\
\text { pós-esforço, atrofia muscular de músculos } \\
\text { respiratórios, do tronco e membros. } \\
\text { Recomenda-se intervenções de exercícios } \\
\text { aeróbios, treinamento de força com } \\
\text { resistência progressiva, equilíbrio, exercício } \\
\text { respiratório e orientação nas atividades de } \\
\text { vida diária (AVD's). }\end{array}$ \\
\hline 2020 & SPAGNOLO et al. & $\begin{array}{l}\text { Verificar a ocorrência de } \\
\text { fibrose pulmonar como } \\
\text { comorbidades secundária a } \\
\text { COVID-19. }\end{array}$ & Ensaio científico. & $\begin{array}{l}\text { No momento, as consequências pulmonares } \\
\text { de longo prazo da COVID-19 permanecem } \\
\text { especulativas e não devem ser assumidas sem } \\
\text { um estudo prospectivo apropriado. No } \\
\text { entanto, dado o grande número de indivíduos } \\
\text { afetados pelo COVID-19, mesmo }\end{array}$ \\
\hline
\end{tabular}




\begin{tabular}{|l|l|l|l|l|}
\hline & & & & $\begin{array}{l}\text { complicações raras terão efeitos importantes } \\
\text { para a saúde a nível da população. É } \\
\text { importante que sejam feitos planos agora } \\
\text { para } \\
\text { identificar rapidamente se o } \\
\text { desenvolvimento de fibrose pulmonar ocorre } \\
\text { na população de sobreviventes }\end{array}$ \\
\hline 2021 & $\begin{array}{l}\text { SANTANA; } \\
\text { FONTANA; PITTA. }\end{array}$ & $\begin{array}{l}\text { Descrever alguns princípios } \\
\text { de reabilitação para pacientes } \\
\text { pós covid-19. }\end{array}$ & $\begin{array}{l}\text { As diretrizes atuais de reabilitaça para essa } \\
\text { população são baseadas principalmente em } \\
\text { resultados preliminares, na opinião de } \\
\text { especialistas e em evidências prévias sobre } \\
\text { reabilitação de pacientes sobreviventes de } \\
\text { doenças críticas. }\end{array}$ \\
\hline
\end{tabular}

Fonte: Autoria própria.

\section{DISCUSSÃO}

Em dezembro de 2019 jamais poderia se imaginar que na cidade de Wuhan, China, silenciosamente dava-se inicio ao evento que em poucos meses viria a se tornar uma das maiores pandemias e cenário de calamidade na saúde pública mundial. Em virtude de seus aspectos clínicos, os primeiros casos foram relatados como pneumonia de etiologia desconhecida e sendo assim proposta uma terapêutica voltada para intervenções antibacterianas convencionais, que logo não respondiam da maneira esperada, pois não se tratava apenas de uma pneumonia, mas da modificação de um vírus do gênero betacoronavírus isolado pela primeira vez em 1937 e 1965 (OLIVEIRA; LUCAS; IQUIAPAZA, 2020).

De origem zoonótica, o novo coronavírus posteriormente intitulado de SARS-CoV-2, tem por principal hospedeiro os animais silvestres como os morcegos do gênero rhinolophus, já sendo presente na literatura a forte sugestão destes mamíferos como o principal habitat e interceptor da cepa viral aos seres humanos. Dessa forma, foi analisada a possibilidade de transmissão por meio apenas do contato ou ingestão do animal contaminado, já que $60 \%$ dos primeiros casos registrados tinham visitado o mercado de frutos do mar na cidade de Wuhan que concentrava fluxo continuo no comercio do alimento infectado. No entanto, um aumento no número de casos não relacionados ao local surgiu e trouxe à tona a possibilidade de outras formas de contaminação. Atualmente estudos já comprovam que os meios de transmissão incluem não só o já citado anteriormente, mas principalmente contato de gotículas contaminadas e aerossóis (ACOSTA et al., 2020; PIMENTEL et al., 2020; OPAS; OMS, 2020a).

A disseminação por contato de gotículas ocorre de forma direta, indireta (fômites, ou seja, objetos e superfícies potencialmente infectados) ou por proximidade com paciente enfermo através de secreções expelidas durante tosse, espirro, fala ou canto, sendo que tais partículas apresentam alcance de pelo menos um metro de distancia e dentro desses limites uma infecção é extremamente provável. Enquanto que os aerossóis formam os núcleos de gotículas que permanecem infectados e suspensos no ar por longas distâncias e tempo após eliminação no meio ambiente, durante procedimentos cirúrgicos ou em locais mal ventilados e fechados (OPAS; OMS, 2020a). 
As estratégias de saúde pública relatam as vastas dificuldades no controle da taxa de disseminação por parte dos indivíduos assintomáticos, que incubam e transmitem o vírus não apresentando qualquer sintoma ou sinal clinico da COVID-19, dificultando sua detecção e isolamento. Bem como pela transmissão pré-sintomática dos infectados que ainda não desenvolveram sintomas, sendo tal informação sustentada por estudos realizados dentro desta temática como a pesquisa promovida por Luo et al. (2020), apesar das pessoas com sintomas de expectoração apresentarem maior capacidade de transmissibilidade (OPAS; OMS, 2020a).

A ECA2 (enzima conversora de angiotensina tipo 2) tem papel extremamente importante quando se trata da possível permeação do patógeno no organismo humano, pois é por meio da ligação do SARS-CoV2 com o receptor desta enzima que esse processo ocorre, dando inicio assim as primeiras etapas da infecção viral na célula-alvo causando uma resposta imunológica e desencadeando os sinais clínicos da doença. O pulmão é o primeiro e principal local de instalação do vírus, contudo, outros órgãos que também apresentam este receptor podem ser acometidos e consequentemente gerar manifestações específicas. Sendo assim, pode-se dizer que a COVID-19 é uma patologia de abordagem sistêmica em que deve ser considerada a disseminação do vírus entre órgãos vitais para se estabelecer um prognóstico fidedigno e otimista (CAMPOS et al., 2020).

O quadro clínico inicial é bastante semelhante ao da influenza em que corre predominantemente febre, tosse, dispneia, fadiga e mialgia. Um estudo realizado na cidade de Wuhan, China, por Huang et al. (2020) com 41 pacientes infectados com o novo coronavírus, analisou as características sintomáticas destes indivíduos em que a febre esteve presente em $98 \%$ dos casos seguido por tosse (76\%), dispneia (55\%) e mialgia/fadiga (44\%). Uma revisão sistemática e meta-análise feita por Morales et al. (2020) também apresentou dados similares, em que os achados clínicos mais comuns foram febre $(88,7 \%)$, tosse $(57,6 \%)$ e dispneia (45,6\%). Todavia, a pirexia nem sempre é o sintoma predominante, outros sinais clínicos apesar de menos frequentes podem se desenvolver como a disgeusia (alteração do paladar) e hiposmia (diminuição do olfato), em decorrência da significativa presença de enzimas da ECA2 nas células epiteliais da mucosa na cavidade oral (GIACOMELLI et al., 2020).

Outros sintomas típicos relatados, mas que não estarão necessariamente sempre presentes, referemse a dor de garganta, congestão nasal, cefaleia e erupção cutânea além daqueles relacionados ao trato gastrointestinal (TGI) como diarreia, náusea, vômitos e dor abdominal. Além de apresentar os sintomas de forma branda esta doença respiratória pode desencadear uma evolução grave do indivíduo acometido, principalmente na presença de comorbidades subjacentes como patologias do sistema cardiovascular, diabetes mellitus, hipertensão arterial, obesidade, problemas renais, doença pulmonar obstrutiva crônica (DPOC) e outras afecções do sistema cardiorrespiratório (ISER et al., 2020; ALMEIDA; CHEHTER, 2020; CAMPOS et al., 2020). 
Pelo menos $15 \%$ dos casos sintomáticos desenvolvem manifestações clínicas graves necessitando de oxigenoterapia e 5\% evoluem para estado crítico em ambiente de Unidade de Terapia Intensiva (UTI), em que há manejo de intervenções invasivas e presença de pelo menos uma ou mais destas complicações: insuficiência respiratória, síndrome do desconforto respiratório agudo (SDRA), sepse, choque séptico, tromboembolismo, insuficiência renal aguda, insuficiência hepática, choque cardiogênico, miocardite, ou acidente cerebrovascular (OPAS, OMS; 2020b).

Os pacientes com necessidade de internação em UTI demandam maior atenção assistencial integral e apoio médico 24horas, principalmente pelas altas taxas de mortalidade e facilidade no desenvolvimento de patologias secundárias a COVID-19 em decorrência do longo período de internação. A intubação e ventilação mecânica (VM) são intervenções que podem se utilizadas com o intuito de restabelecer a capacidade respiratória que se encontra ineficaz, como demonstra um estudo na China em que a VM foi necessária em $6,1 \%$ dos pacientes. Estes indivíduos estão suscetíveis a serem acometidos pela síndrome pós-cuidado intensivo, resultante das complicações secundárias aos procedimentos invasivos ou não ao qual foram submetidos como VM, uso de sedativos, bloqueio neuromuscular e imobilização por longos períodos, comprometendo o condicionamento físico e respiratório, perda de massa muscular, distúrbios cognitivos e neuropsiquiátricos (GUAN et al., 2020; SILVA; PINA; ORMOND, 2021; CORNELY; ROCHA, 2020).

Apesar dos pulmões representarem o órgão-alvo, a hipóxia e resposta inflamatória afetam órgãos como: rins, fígado, TGI, coração, sistema nervoso e hematopoiético. As sequelas neurológicas mais simples estão relacionadas às disfunções olfativas e gustativas persistentes, pelo acometimento de células nervosas responsáveis por tais funções já que ao entrar no organismo pela via olfatória o vírus se direciona e infecta o Sistema Nervoso Central (SNC), migrando para o bulbo olfativo e outras regiões cerebrais como córtex, gânglios da base e o mesencéfalo. Além destas afecções outras queixas foram documentadas como cefaleia, tontura e sensação de raciocínio lento. Com relação às manifestações mais graves o déficit neurológico é mais comumente relatado, sendo também descrita ocorrência de acidente vascular isquêmico (AVI), convulsões, encefalite e neuropatias cranianas, todavia, em situações raras (CAMPOS et al., 2020; NUNES et al., 2020; CORNELY; ROCHA, 2020).

Considerando o sistema respiratório, as alterações em longo prazo dependem da gravidade e extensão da infecção viral, em que ocorre consequente redução da capacidade de difusão do monóxido de carbono, limitação da capacidade nas práticas de exercícios físicos, até mesmo desenvolvimento de fibrose pulmonar em quadros agudos da doença. As causas de tais danos no tecido pulmonar ainda não são completamente conhecidas, porém, estudiosos já exploram explicação que envolve liberação de citocinas proporcionadas pelo SARS-CoV-2, toxicidade pulmonar, alta pressão nas vias aéreas e lesão pulmonar aguda subjacente a VM (MOURA et al., 2021; SPAGNOLO et al., 2020). A fadiga e dispneia são queixas 
recorrentes e comuns em pacientes pós-COVID, uma pesquisa feita na Itália por Carfi et al. (2020) mediante acompanhamento contínuo desses indivíduos recuperados, publicou dados em que a presença persistente de pelo menos um sintoma foi referida por $87,4 \%$ e $53,1 \%$ indicaram ainda a fadiga como sintoma mais frequente, seguido da dispneia $(43,3 \%)$.

As sequelas a nível cardiovascular envolvem agravos produzidos pelas complicações pulmonares, além da presença de comorbidades cardíacas elevarem significativamente as chances de acometimento do tecido, que provavelmente ocorre pela presença de enzimas da ECA2 nos cardiomiócitos e pericitos possibilitando a entrada do antígeno viral e sua replicação. Sendo relatada principalmente lesão miocárdica, frequentemente associada ao dano produzido diretamente sobre os cardiomiócitos, inflamação sistêmica, fibrose intersticial miocárdica e hipóxia (OPAS; OMS, 2020b).

A limitação musculoesquelética se apresenta como uma das principais queixas pós-COVID acometendo pelo menos $25 \%$ dos sobreviventes, extremamente relacionada à perda de força muscular e sarcopenia que ocorre em função da resposta inflamatória ao agente etiológico infeccioso, nutrição insuficiente, e imobilidade muitas vezes associada ao prolongado período de internação. As consequências são perceptíveis na realização de AVDs e qualidade de vida dessas pessoas pelo comprometimento físicofuncional. Um relato pessoal publicado na Radis por Peres (2020) traz à tona a realidade de muitas pessoas que foram vitimas da COVID-19, que mesmo após recuperação e alta hospitalar se queixavam da persistência de alguns sintomas da doença, a entrevistada relatou que após 42 dias da infecção ainda não apresentava melhora, citando a fadiga, mal-estar, enjoo e parosmia como principais manifestações clínicas (GREVE et al., 2020; CAMPOS et al., 2020).

O desenvolvimento de distúrbios mentais já é evidenciado em consequência ao cenário de instabilidade econômica e social que o país se encontra, entre pacientes internados ou em reabilitação esse risco é ainda maior podendo ultrapassar 60\% e abrangendo depressão, ansiedade e estresse pós-traumático. O isolamento social, sofrimento e medo pelo risco potencial de morte são fatores decisivos que ocasionam as sequelas psicológicas da COVID-19 (CAMPOS et al., 2020).

Mediante todas as informações expostas, a reabilitação é primordial para recuperação dos déficits físicos, funcionais e mentais promovida por meio de uma equipe multidisciplinar, essencialmente pela atuação do profissional de educação física e fisioterapeuta, enfatizando a promoção da saúde com o intuito de otimizar a independência e capacidade do paciente. A recuperação deve contemplar: fisioterapia motora ou respiratória, nutrição, fonoaudiologia, terapia ocupacional e apoio psicossocial, levando sempre em consideração as necessidades subjetivas de cada indivíduo (SILVA; PINA; ORMOND, 2021; SANTANA; FONTANA; PITTA, 2020).

Aos que apresentam sintomas prolongados de fadiga e dispneia é indicado inclusão no programa de reabilitação cardiopulmonar, visando redução dessas deficiências no sistema respiratório e cardíaco. Em 
casos de anosmia persistente intervenções farmacológicas ainda não foram desenvolvidas, no entanto, a recomendação terapêutica mais eficaz evidenciada em situações semelhantes é o treinamento olfatório, ou seja, a tentativa de regeneração dos neurônios afetados pela exposição repetida a odores (DANIEL et al., 2020; CORNELY; TORRES, 2020).

A prescrição de exercícios de baixo ou moderado impacto pode ser também necessária, realizada por meio de acompanhamento profissional e incluindo exercícios de força muscular respiratória e periférica, flexibilidade, treino de marcha e equilíbrio. De modo a estimular a contínua execução destas práticas a fim de minimizar riscos futuros como sedentarismo, que atualmente corresponde a um dos fatores de risco que mais predispõe comorbidades (DANIEL et al., 2020).

As condições psiquiátricas devem ser estrategicamente acompanhadas pela promoção de atendimento holístico a esse paciente. Uma alternativa a ser explorada é a adoção da telerreabilitação que emprega a telecomunicação no tratamento de forma remota, agindo na redução de danos pela praticidade de tempo e lugar característica importante pela situação de distanciamento social vigente. Por fim, não só a atuação da equipe multidisciplinar é significativa como também apoio familiar e adesão ao tratamento pelo paciente, cumprindo corretamente as orientações e instruções médicas e sendo respeitada as suas necessidades e singularidades, resultando em posterior reintegração social (SANTANA; FONTANA; PITTA, 2020).

A constante produção cientifica e apoio da comunidade acadêmica sobre temáticas referentes à COVID-19 são imprescindíveis, pelo alto grau de morbimortalidade que essa doença respiratória tem provocado em todo mundo e progressão da história natural da doença ainda em andamento, para que assim, possamos compreender melhor o que nos afeta e agir de forma eficaz e segura não só evitando perdas econômicas e sociais, mas principalmente a perda de vidas humanas (CAMPOS et al., 2020).

\section{CONCLUSÃO}

Mediante explanação das informações supracitadas, torna-se evidente a variedade de sequelas que a COVID-19 é capaz de proporcionar às pessoas que foram infectadas, resultante de sua abordagem multissistêmica que acomete não só o tecido pulmonar, mas sistemas subjacentes e vitais como o cardiovascular, musculoesquelético, neurológico e psicológico. O comprometimento da qualidade de vida é consideravelmente alto pela redução da capacidade funcional e física, além do desgaste emocional e psicológico evidenciado nesses indivíduos. À vista disso, uma reabilitação integral e supervisionada fará toda a diferença, repercutindo consequentemente em um bom prognóstico e devolvendo aos pacientes sua independência e capacidade funcional, ou pelo menos reduzir os danos persistentes. 
Sendo assim, o contínuo estimulo as práticas preventivas, sejam elas individuais ou coletivas, fazse essencial para a proteção da população de modo a diminuir a disseminação viral e número de vitimas que infelizmente não resistem à luta travada contra esse patógeno ainda pouco conhecido. 


\section{REFERÊNCIAS}

AVILA, P.E.S.; PEREIRA, R.dos.N.; TORRES, D.da.C. Guia de orientações fisioterapêuticas na assistência ao paciente pós-COVID-19. Belém: UFPA, FFTO, Curso de fisioterapia, 2020.

ACOSTA et al. Interfaces à transmissão e spillover do coronavírus entre florestas e cidades. Estudos Avançados, São Paulo, v.34, n.99, 2020.

ALMEIDA, J.F.M.de; CHEHTER, E.Z. COVID-19 e o trato gastrintestinal: o que já sabemos? Einstein, São Paulo, v.18, p. 1-14, 2020.

BRASIL. Painel Coronavírus. 2020. Disponível em: https://covid.saude.gov.br/. Acesso em 24 de maio de 2021.

CARFI, et al. Persistent Symptoms in Patients After Acute COVID-19. JAMA, v.324, n.6, p. 603605. 2020.

CORNELY, A.F.H.; ROCHA, J.G.F.da. Avaliação e Manejo de sintomas prolongados de COVID-19. Universidade Federal do Rio Grande do Sul. Programa de Pós-Graduação em Epidemiologia. TelessaúdeRS (TelessaúdeRS-UFRGS), Porto Alegre: TelessaúdeRS-UFRGS; Outubro de 2020 Disponível em: https://www.ufrgs.br/telessauders/documentos/Avaliacao_e_manejo_de_sintomas_prolongados_co vid.pdf. Acesso em 25 de maio de 2021.

CAMPOS, et al. Carga de doença da COVID-19 e de suas complicações agudas e crônicas: reflexões sobre a mensuração (DALY) e perspectivas no Sistema Único de Saúde. Cadernos de Saúde Pública, v.36, n.11, 2020.

DANIEL, et al. Estamos olhando para os indivíduos pós-COVID como deveríamos? Revista de Pesqui. Fisioter., Salvador, v.10, n.4, p. 588-590, 2020.

GIACOMELLI, et al. Self-reported Olfactory and Taste Disorders in Patients With Severe Acute Respiratory Coronavirus 2 Infection: A Cross-sectional Study. Diseases Society of America, v. 71, n.15, p.889-890, 2020.

GREVE, et al. Impacts of covid-19 on the immune, neuromuscular, and musculoskeletal systems and rehabilitation. Revista Brasileira de Medicina do Esporte, v. 26, n.4, 2020.

GUAN, et al. Clinical Characteristics of Coronavirus Disease 2019 in China. The New England Journal of Medicine, v. 382, p. 1708-1720, 2020.

HUANG, et al. Clinical features of patients infected with 2019 novel coronavirus in Wuhan, China. The Lancet, v.395, p. 497-506, 2020.

ISER, et al. Definição de caso suspeito da COVID-19: uma revisão narrativa dos sinais e sintomas mais frequentes entre os casos confirmados. Epidemiol. Serv. Saude, Brasília, v. 29, n. 3, 2020.

LUO, et al. Modes of contact and risk of transmission in COVID-19 among close contacts. Disponível em: https://doi.org/10.1101/2020.03.24.20042606. Acesso em 24 de maio de 2021. 
MORALES, et al. Clinical, laboratory and imaging features of COVID-19: A systematic review and metaanalysis. Travel Medicine and Infectious Disease, v.34, 2020.

MOURA, et al. Sequelas da COVID-19: Evidência Atual. Revista Medicina Desportiva informa, v.12, n.3, p. 8-11. 2021

NOGUEIRA, J..V.D; SILVA, C.M.da. Conhecendo a origem do SARS-CoV-2 (COVID-19). Revista Saúde e Meio ambiente- RESMA, Três Lagoas, v.11, n.2, p. 115-124, agosto/dezembro, 2020.

NUNES, et al. Alterações Neurológicas n Sistemática a Covid-19: uma Revisão Sistemática. Revista Neurociências, Mossoró, 28, p.1-22, 2020.

OLIVEIRA, A.C.de; LUCAS, T.C.; IQUIAPAZA, P.A. O que a pandemia da covid-19 tem nos ensinado sobre adoção de medidas de precaução? Texto \& Contexto Enfermagem, Belo Horizonte- minas Gerais, v. 29, 2020.

OPAS, Organização Pan-Americana da Saúde; OMS, Organização Mundial da Saúde. Transmissão do SARS-CoV-2: implicações para as precauções da prevenção e infecção, 2020a. Disponível em: https://iris.paho.org/bitstream/handle/10665.2/52472/OPASWBRACOVID1920089_por.pdf?sequence=1\&isAllowed=y. Acesso em 22 de maio de 2021.

OPAS, Organização Pan-Americana da Saúde; OMS, Organização Mundial da Saúde. Alerta epidemiológico: complicações e sequelas da COVID-19. 12 de agosto de 2020b. Disponível em: https://www.paho.org/bra/dmdocuments/covid-19-materiais-de-comunicacao-

1/Alerta\%20epidemiologico\%20-\%20Complicacoes\%20e\%20sequelas\%20da\%20COVID-19.pdf. Acesso em 27 de maio de 2021.

PERES, A.C. Dias que nunca terminam: sintomas persistentes relacionados à Síndrome Pós-Covid surpreendem pacientes e pesquisadores. RADIS: Comunicação e Saúde, n. 218, p. 26-31, nov. 2020.

PIMENTEL et al. A disseminação da covid-19: um papel expectante e preventivo na saúde global. Journal Of Human Growth And Development, v.30, n.1, p. 135-140, 2020.

SILVA, L.C.deO; PINA, T.dos.A; ORMOND, L.de.S. Sequelas e reabilitação pós-covid19: revisão de literatura. Revista das Ciências da Saúde e Ciências aplicadas do Oeste Baiano, Higia, v.6, n.1, p. 169184, 2021.

SPAGNOLO, et al. Pulmonary fibrosis secondary to COVID-19: a call to arms? The Lancet, v. 8, n. 8, p. 750-752, 2020.

SANTANA, A.V.; FONTANA, A.D.; PITTA, F. Reabilitação pulmonar pós-COVID-19. Jornal Brasileiro de Pneumologia, v.47, n.1, 2021. 